\title{
O PROFESSOR NO DISCURSO DE DOCENTES DE ENSINO A DISTÂNCIA ${ }^{1}$
}

\author{
Celso Daltin Filho \\ Eliana Maria Severino Donaio Ruiz ${ }^{3}$
}

\section{RESUMO}

Este projeto visa a traçar o imaginário discursivo do professor - que trabalha (ou não) com tecnologia em sala de aula - que emerge de entrevistas com professores pertencentes à esfera de Ensino à Distância (EAD) que atuam ou atuaram na área. Pretendemos analisar, seguindo os pressupostos teóricos da Análise de Discurso de orientação franco-brasileira, como o profissional professor se vê no âmbito social, incluindo tanto aquele que não utiliza a tecnologia no exercício da docência, quanto o docente que trabalha com a educação online ou que se propõe a levar recursos tecnológicos para as suas aulas, na educação presencial.

Palavras-Chave: Discurso, Professor, Ensino a Distância, Representação Imaginária.

\begin{abstract}
This project aims to trace the discursive imaginary teacher - working (or not) with technology in the classroom - that emerges from interviews with teachers belonging to the educational sphere from distance education, who work or worked in this area. We intend to analyze, following the theoretical assumptions of Discourse Analysis of the French-Brazilian orientation, as teacher professional sees himself in the social sphere, including both those who do not use technology in the teaching profession, and the teacher who works with online education or proposes to bring technology to their classes in regular education.
\end{abstract}

Key Words: Discourse, Teacher, Distance Learning, Imaginary Representation.

\section{INTRODUÇÃO}

A inserção massiva da tecnologia na veiculação de informações hoje faz com que cada vez mais haja interesse em incluí-las no convívio social, tanto para uso pessoal quanto para a educação, pelo seu poder de propiciar maior facilidade no trabalho do profissional da educação professor.

Com as novas tecnologias, a atuação do profissional foi atravessada por uma necessidade de modificação. Com isso a imagem desse profissional mudou ou está em transformação, o que pode interferir em sua forma de atuação em sala de aula, seja ela presencial ou

a distância.

\footnotetext{
${ }^{1}$ Trabalho de Iniciação Científica financiado pelo CNPq e orientado pela Profa. Dra. Eliana Maria Severino Donaio Ruiz.

${ }^{2}$ Graduando do terceiro ano de Letras - Língua Portuguesa - UEL. celsodaltinf7@yahoo.com.br.

3 Professora do Departamento de Letras Vernáculas e Clássicas e do Programa de Pós-graduação em Estudos da Linguagem - Universidade Estadual de Londrina. elianaruiz@uel.br.
} 


\section{SEMINÁRIO DE PESQUISA EM CIÊNCIAS HUMANAS - SEPECH \\ Humanidades, Estado e desafios didático-científicos \\ Londrina, 27 a 29 de julho de 2016}

Nosso interesse, neste trabalho, está ligado ao modo como as demandas das novas tecnologias têm interferido na construção do imaginário discursivo acerca do professor enquanto profissional, de modo a nos permitir vislumbrar possíveis diferenças (ou semelhanças) entre a imagem que se tem acerca dos professores que atuam na modalidade de ensino presencial e a construída acerca daqueles que atuam na modalidade de ensino a distância.

Cabe colocar aqui que este trabalho é parte de um projeto maior, EnsinoAprendizagem de Língua Portuguesa na Educação Presencial e Online: Múltiplos Olhares, que visa traçar perspectivas discursivas acerca de diferentes imaginários, tanto do professor como do aluno, que se encontram no âmbito da educação (RUIZ, 2013).

O que nos interessa é como o profissional professor, que tem (ou não) se modificado para se adaptar às mudanças tecnológicas, tem sido visto por professores de Ensino a Distância (EaD). Para tanto, analisaremos entrevistas com docentes da área que, em seus dizeres, elucidam os possíveis papéis aos quais o professor, de maneira geral, está submetido, procurando vislumbrar como esses profissionais são ali representados discursivamente e como as demandas da educação online contribuem para a formação discursiva acerca de docentes que trabalham ou não com recursos tecnológicos digitais na educação.

O objetivo geral do projeto maior a que nos vinculamos e, evidentemente, também deste artigo é contribuir com a reflexão acerca da visão de professor na educação presencial e a distância, sobretudo no ensino-aprendizagem da Língua Portuguesa, permitindo que se lancem novos olhares inclusive sobre práticas educacionais tradicionais e sobre a formação do professor de Língua Portuguesa e de outras linguagens.

Já o objetivo específico deste trabalho é traçar o imaginário discursivo acerca de professores que trabalham ou não com tecnologia atualmente. Tal imaginário emerge de entrevistas gravadas com docentes ligados ao ensino a distância, a partir de uma análise discursiva que procura analisar como a materialidade linguística revela a visão do profissional professor sobre si e o imaginário social a respeito do mesmo.

As entrevistas presentes no corpus foram transcritas e posteriormente analisadas, com base nos pressupostos da Análise de Discurso (AD) de vertente franco-brasileira que visam dessuperficializar o objeto discursivo, isto é, encontrar, via gestos interpretativos do analista, enunciados que emergem dos discursos analisados.

Faremos possíveis interpretações dos efeitos de sentido que emergem dos dizeres nas entrevistas com os docentes de $\mathrm{EaD}$, procurando explicitar o não dito naquilo que é dito. A análise se baseará nas seguintes perguntas de pesquisa:

- quais são os efeitos de sentido das representações de professor que emergem das entrevistas que tematizam as modalidades de ensino presencial e a distância?

- que discursos se entrecruzam nessas representações?

- que relações é possível estabelecer entre o discurso (acerca) do ensino presencial e o discurso (acerca) da educação a distância?

\section{UMA PALAVRA SOBRE A ANÁLISE DE DISCURSO}

Para adentrarmos brevemente no campo teórico que fundamenta este trabalho, faremos considerações sobre a linha francesa de estudos discursivos, que tem Pêcheux (1990[1969]) como precursor, concebendo o discurso como um processo sócio- 


\section{SEMINÁRIO DE PESQUISA EM CIÊNCIAS HUMANAS - SEPECH \\ Humanidades, Estado e desafios didático-científicos \\ Londrina, 27 a 29 de julho de 2016}

ideológico que trata tanto de aspectos subjetivos, no que diz respeito ao sujeito discursivo e aos fatores que o constituem como tal, quanto de aspectos históricos, no que se refere às características de exterioridade constitutivas do discurso. O discurso é, pois, tratado aqui como um objeto sócio-histórico-ideológico atravessado por sentidos que são construídos historicamente e que estão na memória da sociedade.

Por esse motivo, também, ressaltamos que a $\mathrm{AD}$ de linha franco-brasileira, dada a abordagem que se consolidou no Brasil, lida com o aspecto dos sentidos em um discurso que está em movimento, pois se constitui como tal de acordo com o processo sócio-histórico de formações sociais. $\mathrm{Na}$ medida em que enxergamos o discurso enquanto objeto material que tem relação com a história e com o sujeito discursivo, percebemos que ele atua na materialidade das relações sociais.

Diferentemente de outras correntes linguísticas que abordam o sentido constituinte de um sistema pré-estabelecido, na $\mathrm{AD}$ emergem três eixos nodais do dizer para uma configuração de um processo discursivo: o sujeito, a ideologia e o discurso, que se interligam por meio das relações simbólicas que estão presentes na sociedade.

Para entendermos o que é discurso e o sujeito discursivo, precisamos nos atentar ao que é ideologia, instância que se entrelaça com esses dois eixos da teoria discursiva, na medida em que compõe um construto de ideias presentes no interior de uma formação social, como aponta Chauí (2006, p. 13):

[...] a ideologia não é sinônimo de subjetividade oposta à objetividade, que não é pré-conceito nem pré-noção, mas que é um "fato" social justamente porque é produzida pelas relações sociais, possui razões muito determinadas para surgir e se conservar, não sendo um amontoado de ideias falsas que prejudicam a ciência, mas uma certa maneira da produção das ideias pela sociedade, ou melhor, por formas históricas determinadas das relações sociais.

Nessa ótica, sobre o caráter predominantemente social da ideologia, enquanto fenômeno ocorrido por meio de prescritivas sócio-históricas engendradas pelas relações sociais, percebemos, à luz da teoria discursiva, que esse aspecto é essencial para compreendermos o funcionamento de um discurso, pois este se processa pela disposição de forças ideológicas que atuam num dado momento da história.

\subsection{O Sujeito Discursivo e sua Identidade: o Papel do Imaginário Discursivo e das Representações Sociais}

Como dissemos, para a $\mathrm{AD}$, existem três eixos nodais para a configuração de um processo discursivo em sua materialidade: o sujeito, a ideologia e o discurso. Em se tratando especificamente do sujeito, que não é o indivíduo, mas que "é interpelado em sujeito pela ideologia" (ORLANDI, 2007, p.17), vemos que o que o faz existir é a junção de fatores de ordens diferentes que não são nomeados a priori: o inconsciente e o aspecto ideológico.

Com base nesses dois conceitos, o que enxergamos, na medida em que analisamos a presença ou a atuação da identidade do sujeito discursivo, é a própria heterogeneidade que o constitui como tal, mais especificamente nas próprias contradições do sujeito, como aponta Fernandes (2008): 


\title{
XI SEMINÁRIO DE PESQUISA EM CIÊNCIAS HUMANAS - SEPECH \\ Humanidades, Estado e desafios didático-científicos \\ Londrina, 27 a 29 de julho de 2016
}

A heterogeneidade constitutiva do sujeito, reiterada nas diferentes identidades, algumas contraditórias, outras inacabadas e algumas ainda por se produzirem, e nenhuma fixa, todas moventes, revelamnos a complexa constituição do sujeito no discurso. (FERNANDES, 2008, p. 33)

Essa construção movente da identidade do sujeito abrange a instância da ideologia enquanto fator que opera no sujeito, à qual ele se assujeita no interior de uma formação social que lhe é dada no momento em que assume o papel de sujeito do discurso. $\mathrm{O}$ modo como ele concebe as relações sociais e se coloca perante elas revela seu posicionamento, que é compartilhado por um grupo de indivíduos interpelados em sujeitos.

Nesse ponto de observação de um possível questionamento sobre como se dão as relações entre o processo de identificação de um sujeito, que abarca um viés psicanalítico e a ideologia, no que diz respeito ao seu posicionamento, SILVA (2009) aponta que o assujeitamento do sujeito ao discurso constitui sua própria identidade. Conforme o autor:

\begin{abstract}
Os sujeitos são, assim, sujeitados ao discurso e devem, eles próprios, assumi-lo como indivíduos que, dessa forma, se posicionam a si próprios. As posições que assumimos e com as quais nos identificamos constituem nossas identidades. A subjetividade inclui as dimensões inconscientes do eu, o que implica a existência de contradições. (SILVA, 2009, p.55)
\end{abstract}

A partir da consideração do autor de que o sujeito se identifica através de um assujeitamento, percebemos também que esse processo que o sujeito sofre, seja do meio social, quanto de sua subjetividade, existe de acordo com o modo com o qual o sujeito representa o mundo. $\mathrm{O}$ direcionamento para se pensar os processos sócio-históricos que permeiam o sujeito emerge através de uma ideologia dominante na subjetividade do sujeito, na medida em que ele se constitui como agente de uma discursividade.

Em se tratando daquilo que é produzido pelo sujeito no discurso, cabe notar em que medida a noção de imaginário discursivo e de representação estão concomitantemente ligados no processo discursivo como um todo. Eles trabalham com as relações simbólicas inseridas nas formações sociais (propiciadas pelas condições de produção) que configuram o andamento do discurso.

O imaginário se refere ao que se é pensado sobre algo na sociedade e é construído a partir de perspectivas sócio-ideológicas que se tem de determinado grupo, pessoa ou instância social. Enquanto constituinte de um processo em que o já dito e o já ouvido o atravessam quanto à sua percepção no discurso, o imaginário é formado por diferentes representações que emergem no discurso a partir de outro lugar que fala anteriormente nas diferentes formações imaginárias que o sujeito pode ter.

Essas formações, conforme Pêcheux e Fuchs (1997[1975], p. 85),

[...] resultam, elas mesmas, de processos discursivos anteriores (provenientes de outras condições de produção) que deixaram de funcionar mas que deram nascimento a "tomadas de posição" implícitas que asseguram a possibilidade do processo discursivo em foco. 


\section{SEMINÁRIO DE PESQUISA EM CIÊNCIAS HUMANAS - SEPECH \\ Humanidades, Estado e desafios didático-científicos \\ Londrina, 27 a 29 de julho de 2016}

Levando em conta essas posições como lugares em que existem percepções, estas vindas dos lugares pertencentes à instância de discurso, Pêcheux (1990[1969], p. 85) também aponta que “a percepção é sempre atravessada pelo 'já ouvido' e pelo 'já dito' através dos quais se constitui a substâncias das formações imaginárias enunciadas".

Ligada a esta concepção de imaginário discursivo, enquanto referência a uma representação que existe na memória social e nas condições de produção, ressaltamos que a noção de representação atrelada ao jogo de identidades que emergem na sociedade se faz pelo par identidade e diferença. Esse par, na perspectiva discursiva, se traduz, para Silva (2009), pelas formações imaginárias que são mantidas pelo papel social que cada um que pertence ao processo discursivo exerce. Conforme o sociólogo,

A identidade e a diferença se traduzem, assim, em declarações sobre quem está incluído e quem está excluído[...]. A identidade está sempre ligada a uma forte separação entre "nós" e "eles". Essa demarcação de fronteiras, essa separação e distinção, supõem e, ao mesmo tempo afirmam e reafirmam relações de poder. (SILVA, 2009, p.82)

A partir da concepção de que as relações de poder estão materializadas nas representações que os sujeitos fazem de si e do(s) outro(s) e das formações imaginárias que tanto os sujeitos como os interlocutores têm, vemos que ambos os conceitos estão atrelados numa perspectiva discursiva que leva em conta o não dito.

\section{A EDUCAÇÃO A DISTÂNCIA (EaD)}

Para elucidar o campo discursivo de que tratamos neste trabalho, cabe, também, mencionar breves noções acerca da modalidade da Educação a Distância $(\mathrm{EaD})$ e, sobretudo, do professor que atua nessa área, no que diz respeito ao seu papel metodológico em relação ao processo de ensino-aprendizagem que se vale substancialmente das tecnologias.

A EaD, na pós-modernidade, se faz presente como um meio flexível de trocas de conhecimentos que ocorrem por meio de aparatos tecnológicos. Para deixar explícita a definição desse campo educacional em seu todo, nos atentemos para a concepção de que esta modalidade difunde e separa os processos de ensino e aprendizagem:

Educação a distância pode ser definida como a família de métodos instrucionais nos quais os comportamentos de ensino são executados em separado dos comportamentos de aprendizagem, incluindo aqueles que numa situação presencial (contígua) seriam desempenhados na presença do aprendente de modo que a comunicação entre o professor e o aprendente deve ser facilitada por dispositivos impressos, eletrônicos, mecânicos e outros. (MOORE, 1973, apud BELLONI, 2006, p. 19)

Conforme apontado pelos autores, a EaD se configura pela prática conjunta de métodos de ensino proporcionada pela interferência das tecnologias. Tal interferência se relaciona com outra necessidade que se faz presente ao professor pertencente a tal esfera: a de estar se atualizando, pois para tratar de um tipo de educação que se realiza 


\section{SEMINÁRIO DE PESQUISA EM CIÊNCIAS HUMANAS - SEPECH \\ Humanidades, Estado e desafios didático-científicos \\ Londrina, 27 a 29 de julho de 2016}

via tecnologia, este tende a se aproximar cada vez mais do cotidiano da vida do aluno ou aprendente.

Belloni (2006, p. 82), em relação à situação de se atuar na $\mathrm{EaD}$, afirma a essencialidade do docente de estar atualizado. Conforme a autora,

[...] o professor terá necessidade muito acentuada de atualização constante, tanto em sua disciplina específica, quanto em relação às metodologias de ensino e novas tecnologias. A redefinição do papel do professor é crucial para o sucesso dos processos educacionais presenciais ou a distância. Sua atuação tenderá a passar do monólogo sábio da sala de aula para o diálogo dinâmico dos laboratórios, salas de meios, e-mail, telefone e outros meios de interação mediativizada $[\ldots]$

Conforme a autora, vemos que a necessidade de o professor de se atualizar consiste em uma redefinição dos processos educacionais quando se refere à maneira dinâmica que o professor tem de ministrar suas aulas. A tecnologia, que faz parte de uma metodologia de ensino pós- moderna, influencia o imaginário que o professor que trabalha com ela atualmente tem sobre si mesmo. É o que veremos na análise a seguir.

\section{A BUSCA PELO IMAGINÁRIO ACERCA DO PROFESSOR EM ENTREVISTAS COM DOCENTES DE ENSINO A DISTÂNCIA}

Com o objetivo de compreender os imaginários acerca do professor de $\mathrm{EaD}$ e também do professor presencial, propusemos um questionário de entrevista tanto para professores que atuam na esfera $\mathrm{EaD}$, como para professores que deram aula nessa modalidade de ensino mas que, no momento, estão atuando no ensino presencial. Ao todo foram entrevistados dez professores, dentre eles, seis atuaram na EaD como docentes, dois ainda atuam e dois atuaram como tutores. $\mathrm{O}$ questionário foi proposto visando investigar a possibilidade da emergência de diversas concepções acerca de ambas as modalidades de ensino e da imagem que se tem acerca do professor enquanto profissional da educação.

Durante as entrevistas gravadas que se basearam no questionário proposto foram feitas dez perguntas abertas aos entrevistados:

1) Você acha que existe um padrão de docência cristalizado (já institucionalizado) no Brasil?

2) Para você, o que é ser um profissional da educação professor nos dias de hoje?

3) Na sua opinião, o que é ser um bom professor, hoje?

4) Para você, existe diferença entre ser um professor de ensino presencial e ser um professor de ensino a distância?

5) $\mathrm{O}$ que você acredita que o professor precisa fazer para ser bem sucedido no ensino presencial?

6) E o que o professor precisa saber fazer para ser bem sucedido no ensino a distância, na sua opinião?

7) Você vê alguma vantagem em ser professor de Ensino a Distância nos dias de hoje?

8) Na sua opinião, quais as vantagens e desvantagens em ser professor no ensino presencial? 


\section{SEMINÁRIO DE PESQUISA EM CIÊNCIAS HUMANAS - SEPECH \\ Humanidades, Estado e desafios didático-científicos \\ Londrina, 27 a 29 de julho de 2016}

9) E, segundo sua opinião, quais são as vantagens e desvantagens de ser professor de ensino a distância nos dias de hoje?

10) Você gostaria de acrescentar algum comentário?

Com base nas respostas a essas perguntas, procuramos investigar o lugar discursivo de onde emergem formações imaginárias acerca do professor atual que trabalha constantemente interpelado pela inserção das tecnologias no meio social dos indivíduos, incluindo aí a educação. Também buscamos desvendar as diferentes representações e interpelações ideológicas do professor que são dadas discursivamente nos dizeres de profissionais da área.

Em meio aos acontecimentos discursivos encontrados nos trechos analisados das respostas das entrevistas, propomos a existência de uma regularidade discursiva configurada por cinco enunciados, a saber : o professor é atravessado por um padrão de docência imposto a ele, o professor está diante de um desafio, o professor é um mediador de conhecimento, o professor é interpelado por diferentes tipos de interação nas modalidades presencial e a distância, o professor precisa estar atualizando suas práticas.

\subsection{O Professor atravessado por um Padrão de Docência Imposto a Ele}

Delimitaremos a presente análise discursiva mostrando como emerge o primeiro dos enunciados apontados acima: "o professor é atravessado por um padrão de docência imposto a ele". Para tanto, focaremos nosso trabalho na tentativa de mostrar como se dá a intervenção ou atravessamento de padrões de docência distintos ao docente que atua na pós-modernidade. Através dessa construção verbal enunciada que se encontra além da superfície do discurso, do que está na materialidade dos textos transcritos das entrevistas, analisamos os efeitos de sentido dos dizeres que mostram diferentes concepções do sujeito professor acerca de suas práticas educacionais.

Para tanto, selecionamos quatro recortes discursivos (RDs), trechos de entrevistas que constituem a materialidade do referido enunciado proposto por nossa interpretação. Esses RDs constituem trechos das entrevistas que julgamos pertinentes para a análise. Entre parênteses, apresentamos informações acerca das condições de produção do dizer em questão (dados sobre a atuação do sujeito, nomeado com iniciais, se professor na modalidade $\mathrm{EaD}$ e se trabalha em instituição pública ou privada).

Começamos por mostrar o primeiro recorte, RD1, no qual se pode notar um reconhecimento acerca do padrão de docência tradicional:

RD 1

(entrevistador): Você acha que existe um padrão de docência cristalizado, já institucionalizado no Brasil?

(entrevistado): Sim, porque principalmente nas instituições públicas, a gente tem um perfil inclusive de material didático pra dar as aulas né, então você acaba tendo que seguir uma série de comportamentos dentro daquele conjunto de materiais que você tem que dar.

No recorte acima, percebemos que há um sujeito da educação que se reconhece enquanto pertencente a um padrão de docência ao qual se submete (você acaba tendo que seguir uma série de comportamentos dentro daquele conjunto de materiais que você tem que dar). Tal padrão de docência pode interpelá-lo também no que diz respeito ao material que ele utiliza para ministrar suas aulas. 


\section{SEMINÁRIO DE PESQUISA EM CIÊNCIAS HUMANAS - SEPECH \\ Humanidades, Estado e desafios didático-científicos \\ Londrina, 27 a 29 de julho de 2016}

Há também a possibilidade de existir um imaginário acerca do material didático e da prática docente específico de instituições públicas ou privadas (principalmente nas instituições públicas, a gente tem um perfil inclusive de material didático pra dar as aulas).

No recorte a seguir, vemos a reafirmação de um padrão cristalizado de docência, mas que também diz respeito ao caráter expositivo das aulas como algo que se enquadra no modelo tradicional de educação:

RD 2

(entrevistador): Você acha que existe um padrão de docência cristalizado, já institucionalizado no Brasil?

(entrevistado): Eu acho que existe, que... esse padrão tradicional né de conteúdo, que você tem que passar um determinado conteúdo de aula extremamente expositiva acho que esse é o padrão cristalizado. " (F.: atuou como professor em instituição privada)

A afirmação de uma cristalização de um padrão de docência (esse é o padrão cristalizado) também pode ser vista em RD2 como algo que atravessa o professor em suas práticas como profissional da educação.

Aqui vemos um sujeito que também se encontra assujeitado a um método de ensino específico, o da aula expositiva (você tem que passar um determinado conteúdo de aula extremamente expositiva) e que reconhece a cristalização do modelo de aula tradicional, no sentido de que o padrão de docência é fechado. Sabemos que existem os professores que se adequam a esse padrão e outros que não adotam tal modelo. A obrigação do profissional docente de exercer um tipo determinado de aula o coloca em uma posição-sujeito que é convocada a se encaixar em um tipo de representação de professor, no caso, o que trabalha com a aula expositiva.

Agora nos atentemos para o recorte a seguir, o qual também afirma um padrão de docência cristalizado que atravessa a prática docente:

RD 3

(entrevistador): Você acha que existe um padrão de docência cristalizado, já institucionalizado no Brasil?

(entrevistado): Então tem essa cristalização, essa institucionalização, o professor é aquele ser dotado de um conhecimento onde ele vai até a sala de aula e transmite aquilo para os alunos, nesse sentido de transmissão do conhecimento de geração né que aí vão ter linhas contrárias como Piaget entre outras" ( D.N: atuou como professor em instituição privada)

Nesse recorte, novamente encontramos uma ligação, exposta no enunciado do entrevistado, entre o padrão cristalizado de docência e uma explicitação do padrão galgado em uma perspectiva tradicional da concepção de professor (o professor $\dot{e}$ aquele ser dotado de um conhecimento onde ele vai até a sala de aula e transmite aquilo para os alunos). Esse imaginário de professor como mero transmissor de conhecimento, criticado por correntes teóricas de formação de professores na atualidade, aparece no discurso docente como uma alternativa não única de metodologia de ensino (nesse sentido de transmissão do conhecimento de geração né que aí vão ter linhas contrárias como Piaget entre outras).

Em vista dessa dualidade de práticas educacionais possíveis ao sujeito professor abre-se a possibilidade de que esse sujeito seja colocado em meio a uma escolha. De maneira que o imaginário de um bom professor, seja na esfera presencial, onde atua o enunciador, ou na esfera a distância, da qual já fez parte, é a daquele que não promove a utilização do modelo tradicional de docência. 


\section{SEMINÁRIO DE PESQUISA EM CIÊNCIAS HUMANAS - SEPECH \\ Humanidades, Estado e desafios didático-científicos \\ Londrina, 27 a 29 de julho de 2016}

No recorte a seguir, se percebe o mesmo fato aludido nos recortes anteriores: o de que o sujeito da educação é atravessado por um padrão de docência e/ou de formação que atravessa suas práticas. Vejamos tal acontecimento em sua materialidade discursiva: RD 4

(entrevistador): Você acha que existe um padrão de docência cristalizado, já institucionalizado no Brasil?

(entrevistado): Em partes, em partes sim por quê? porque toda a estrutura de ensino, o nosso processo de formação [...] foi um um processo histórico de construção social em que os docentes que hoje atuam eles acabam por de alguma forma replicar esse modelo, ou seja, ele tem, em parte sim é: cristalizado[...] esse processo de formação nosso ele acaba por moldar as nossas práticas. (S.F atua como professor de ensino a distância em instituição pública)

Neste último recorte, já há um movimento do enunciador de comparação do processo de formação de professores com o atravessamento de um determinado padrão de docência que, segundo ele, é cristalizado, replicado pelos docentes atualmente (nosso processo de formação [...] foi um um processo histórico de construção social em que os docentes que hoje atuam eles acabam por de alguma forma replicar esse modelo).

Tal concepção da atividade docente, que está presente na memória discursiva tanto do sujeito entrevistado quanto dos que estão imersos na mesma formação discursiva em que se encontra o dizer acima, se constitui em função de uma interpelação do professor por parte da ideologia dos métodos tradicionais de ensino (esse processo de formação nosso ele acaba por moldar as nossas práticas). Vemos aqui que tal ideologia, ao encabeçar o modelo padrão dos processos de formação de professores, atravessa a prática docente atual.

\section{CONSIDERAÇÕES FINAIS}

Em vista da análise desses dizeres, vemos que há uma concordância predominante dos enunciadores acerca da existência de um padrão de docência tradicional no Brasil que atravessa o professor enquanto sujeito da educação, sujeito que se vê inserido em um lugar social que é interpelado por uma dualidade de modelos de práticas metodológicas. O docente é um sujeito que se posiciona de acordo com tal ideologia, a que se subjetiva, escolhendo um dos padrões de exercício da docência que lhe são, de alguma forma, impostos: o tradicional ou o não tradicional.

Algo que se materializa no discurso dos docentes de EaD entrevistados é a concepção da existência de um padrão não tradicional da educação que vigora como uma maneira de prestígio na esfera educacional. O modo de se posicionar frente aos padrões de docência impostos ao professor faz com que haja uma separação entre dois grupos distintos de docente, os que seguem esse padrão e os que não seguem. Existem, no discurso desses professores de $\mathrm{EaD}$ entrevistados, que se adéquam ou não ao padrão tradicional de exercício docente, interdiscursos outros que atravessam o imaginário de um professor bom ou ruim, atualizado ou desatualizado.

Há uma ideologia que rompe com os aspectos tradicionalistas dos métodos de ensino, predominantemente emergente no discurso de docentes que têm um contato maior com a tecnologia. $\mathrm{O}$ posicionamento do professor em relação às práticas educacionais revela sua posição-sujeito localizada no entremeio de métodos tradicionais e não tradicionais de ensino, e de práticas docentes que utilizam ou não a tecnologia, 


\section{SEMINÁRIO DE PESQUISA EM CIÊNCIAS HUMANAS - SEPECH \\ Humanidades, Estado e desafios didático-científicos \\ Londrina, 27 a 29 de julho de 2016}

interpelando o professor enquanto sujeito valorizado ou desvalorizado socialmente na esfera educacional.

\section{REFERÊNCIAS}

BELLONI, Maria Luiza. Educação a distância. Autores Associados, 2006.

CHAUÍ, Marilena. O que é ideologia. São Paulo: Brasiliense, 2006.

FERNANDES, Claudemar Alves. Análise do discurso: reflexões introdutórias, 2008.

PÊCHEUX, Michel. Análise automática do discurso. Tradução de Eni P. Orlandi. In: GADET, Françoise; HAK, Tony. (Org.). Por uma Análise Automática do Discurso: uma Introdução à obra de Michel Pêcheux. Campinas, SP: Editora da UNICAMP, 1990[1969], p. 61-161.

; FUCHS, Catherine. [1975] A propósito da análise automática do discurso: atualização e perspectivas. In: GADET, F.; HAK, T. (Orgs.). Por uma análise automática do discurso. 3. ed. Campinas: Unicamp, 1997, p. 163-252.

ORLANDI, Eni Puccinelli. Análise de Discurso: princípios e procedimentos. 7 ed. Campinas, SP: Pontes, 2007.

RUIZ, Eliana Maria Severino Donaio. Ensino-aprendizagem de Língua Portuguesa na Educação Presencial e Online: Múltiplos Olhares, 2013. Projeto de pesquisa cadastrado na PROPPG - UEL, sob No. 08693. Disponível em: $<$ https://www.sistemasweb.uel.br/system/prj/pes/pdf/pes_pesquisa_08693.pdf $>$. Acesso em: 27 mai. 2016.

SILVA, Tomaz Tadeu da. A produção social da identidade e da diferença. In:

(Org.) Identidade e diferença: a perspectiva dos Estudos Culturais. 9. ed. São Paulo: Vozes, 2009. p. 73-102. 